CONF-960717--2 UCRL-JC-122419

PREPRINT

\title{
Single Stage To Orbit Mass Budgets Derived From Propellant Density and Specific Impulse
}

\author{
John C. Whitehead
}

RECEIVED

JUN 241996

OSTI

This paper was prepared for submittal to 32nd AIAA/ASME/SAE/ASEE Joint Propulsion Conference

Lake Buena Vista, FL

July 1-3, 1996

\section{MASTER}

June 6, 1996

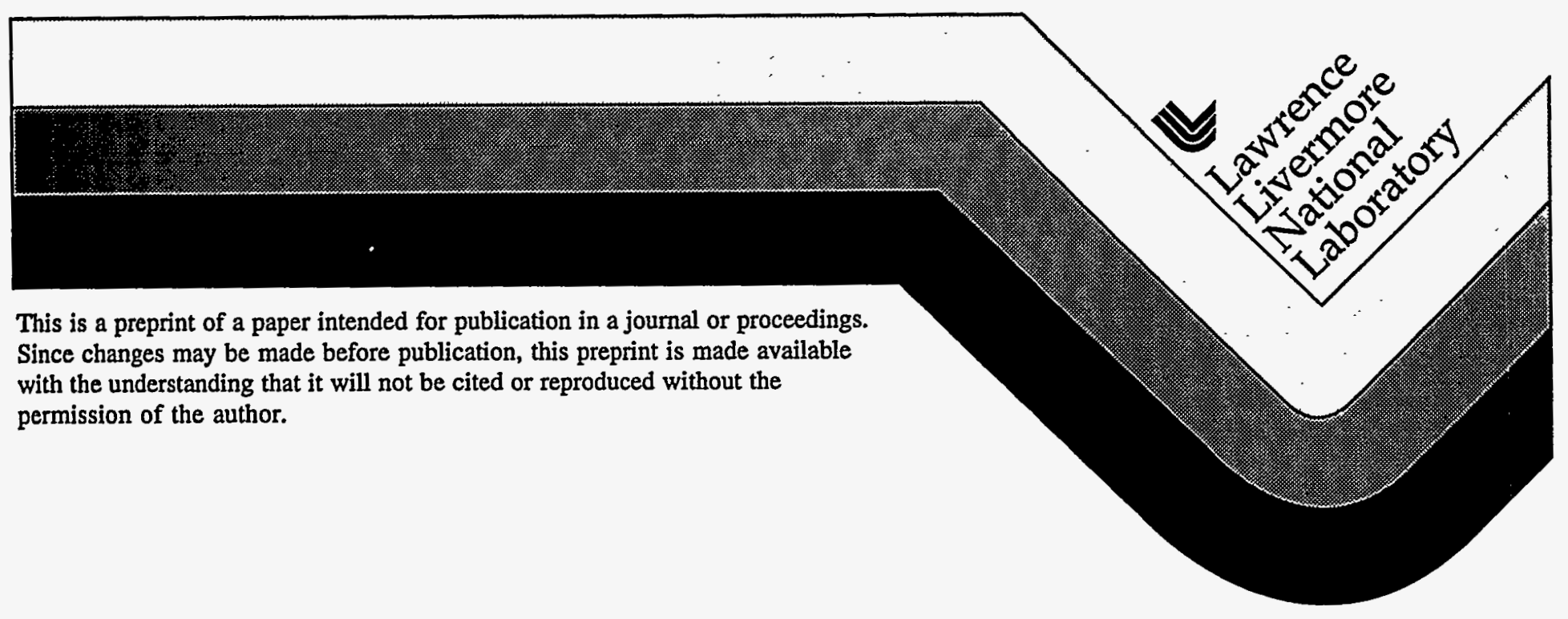




\section{DISCLAIMER}

This document was prepared as an account of work sponsored by an agency of the United States Government. Neither the United States Government nor the University of California nor any of their employees, makes any warranty, express or implied, or assumes any legal liability or responsibility for the accuracy, completeness, or usefulness of any information, apparatus, product, or process disclosed, or represents that its use would not infringe privately owned rights. Reference herein to any specific commercial product, process, or service by trade name, trademark, manufacturer, or otherwise, does not necessarily constitute or imply its endorsement, recommendation, or favoring by the United States Government or the University of California. The views and opinions of authors expressed herein do not necessarily state or reflect those of the United States Government or the University of California, and shall not be used for advertising or product endorsement purposes. 


\section{DISCLAIMER}

This report was prepared as an account of work sponsored by an agency of the United States Government. Neither the United States Government nor any agency thereof, nor any of their employees, makes any warranty, express or implied, or assumes any legal liability or responsibility for the accuracy, completeness, or usefulness of any information, apparatus, product, or process disclosed, or represents that its use would not infringe privately owned rights. Reference herein to any specific commercial product, process, or service by trade name, trademark, manufacturer, or otherwise does not necessarily constitute or imply its endorsement, recommendation, or favoring by the United States Government or any agency thereof. The views and opinions of authors expressed herein do not necessarily state or reflect those of the United States Government or any agency thereof. 



\title{
SINGLE STAGE TO ORBIT MASS BUDGETS \\ DERIVED FROM PROPELLANT DENSITY AND SPECIFIC IMPULSE
}

\author{
John C. Whitehead* \\ Lawrence Livermore National Laboratory \\ Livermore, CA 94551
}

\begin{abstract}
The trade between specific impulse and density is examined in view of SSTO requirements. Mass allocations for vehicle hardware are derived from these two properties, for several propellant combinations and a dual-fuel case. This comparative analysis, based on flight-proven hardware, indicates that the higher density of several alternative propellants compensates for reduced Isp, when compared with cryogenic oxygen and hydrogen. Approximately half the orbiting masis of a rocket-propelled SSTO vehicle must be allocated to propulsion hardware and residuals. Using hydrogen as the only fuel requires a slightly greater fraction of orbiting mass for propulsion, because hydrogen engines and tanks are heavier than those for denser fuels. The advantage of burning both a dense fuel and hydrogen in succession depends strongly on tripropellant engine weight. The implications of the calculations for SSTO vehicle design are discussed, especially with regard to the necessity to minimize non-tankage structure.
\end{abstract}

\section{Introduction}

Ideal chemical rocket propellants would have both high specific impulse (Isp) and high density. Figure 1 graphically illustrates the unfortunate need to choose between these two desirable characteristics when selecting real propellants. Nevertheless, cryogenic oxygen and hydrogen are often assumed to be the best propellants for single-stage-to-orbit (SSTO) rockets. ${ }^{1}$ This is a paradox, in view of the fact that a SSTO vehicle is a first stage, and existing first stages are not fueled by hydrogen.

The use of dense liquids has been advocated in order to enable extremely high propellant mass fractions. Clapp and Hunter calculated that the density of nearly-pure hydrogen peroxide (high test peroxide, HTP) and kerosene makes this propellant combination superior to oxygen and hydrogen. 2 Their approximate calculation assumed that the entire empty mass of a SSTO vehicle scales as propellant volume, which is true only for tanks.

\section{*Senior Member, AIAA}

Copyright 1996 by the Lawreace Livermore National Laboratory. Published by the American Institute of Aeronautics and Astronautics, Inc. with permission.

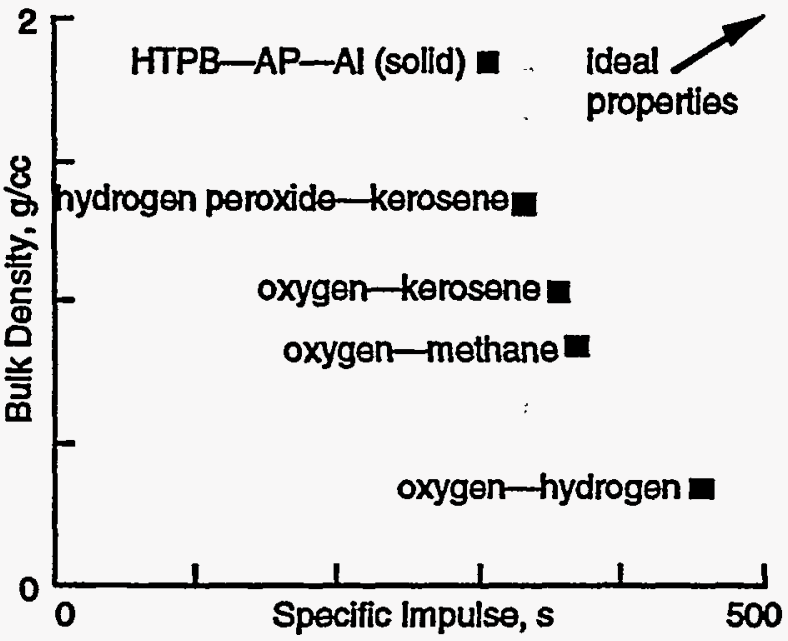

Figure 1. Density and vacuum Isp of propellants.

This paper presents a more accurate comparison of propellants consistent with SSTO requirements. A related goal is to keep the analysis simple, so the calculations can be readily verified and the conclusions are independent of complex or hidden assumptions. Accordingly, historical data for launcher hardware capabilities are used herein. It is hoped that this traceability to reality will permit understanding and appreciation by a wide readership.

It is not easy to derive a figure of merit to quantify the relative importance of Isp and density. As an example, their product merely represents impulse per unit volume, which excessively favors dense propellants having low Isp. To correct for this, the use of density times Isp squared has been proposed. ${ }^{3}$ Here, it is noted that the trade is specific to the mission and to actual hardware capabilities. Thus, a truly accurate figure of merit would necessarily be algebraically complex.

Herein, idealized SSTO mass allocations are derived from propellant density and Isp, given known hardware capabilities and the basic equations which govern rocket design and performance. The intent for the straightforward analysis is to instill "figure of merit" character in the results. Therefore, dimensionless ratios are used instead of assuming a particular vehicle size or payload capacity. The primary intent is to quantify the density-Isp trade. 
Gross launch mass is obviously important for upper stages, which must be lifted and accelerated when full of propellants, but it is fundamentally less important for first stages, including SSTO vehicles. The mass and size of manufactured hardware is a better indicator of cost than gross mass, since propellant is relatively inexpensive. For these reasons, previous papers have advocated judging SSTO vehicle designs on the basis of payload mass as a fraction of empty (hardware) mass, rather than as a fraction of gross mass (hardware + propellants).45 This criterion is adopted here. Residual fluids are also included in the "empty" mass, because the need to carry them to orbit directly affects the payload fraction.

The present work calculates the contributions of engines, tanks, and residual fluids to the orbiting mass of idealized SSTO vehicles. The remaining fraction of orbiting mass represents the allowance for payload, as well as subsystems which are mostly independent of the propellant choice. Solid propellants are initially noted but are beyond the scope of the full analysis, because major hardware differences for solid and hybrid motors increase the difficulty of a fair comparison to liquid systems. The assumptions of low tank pressure ( $<0.5 \mathrm{MPa})$ and pumpfed engines are inherent to the numbers presented in this paper.

Of fundamental importance is the required mass ratio (launch/orbiting), which is dictated by the rocket equation given Isp and the required velocity increment $(\Delta v)$. Higher Isp reduces the required mass of propellant relative to hardware. High propellant density, which is also a key virtue, decreases tank volume, and hence the fraction of orbiting mass which must be devoted to tanks. Although the effect on engines is slightly more subtle, dense liquids reduce the required size of flow passageways, and hence the fraction of vehicle hardware mass which must be reserved for engines and related plumbing.

\section{Propellants and vehicle mass ratios}

For each propellant combination considered, a theoretical value for vacuum Isp is used (chamber pressure $=7 \mathrm{MPa}$, area ratio $=40$ ). A round number, $10 \mathrm{~km} / \mathrm{s}$, is taken as the $\Delta v$ required to reach low earth orbit. It is assumed that the $\sim 2 \mathrm{~km} / \mathrm{s}$ in excess of orbital velocity accounts for gravity and drag losses, as well as a lower delivered Isp. The latter results from engine design realities and atmospheric operation during part of the trajectory.

Table 1 lists selected propellant combinations, their characteristics, and the results of applying the rocket equation. Two key ratios are graphed in Figure 2. From the mass ratios (open bars), it is clear that the Isp variation among the different propellants results in a wide variation in propellant mass for a given orbiting mass. . As a result, hydrogen vehicles have about half the launch mass of the average kerosene SSTO (10x vs $20 \mathrm{x}$ orbiting mass).

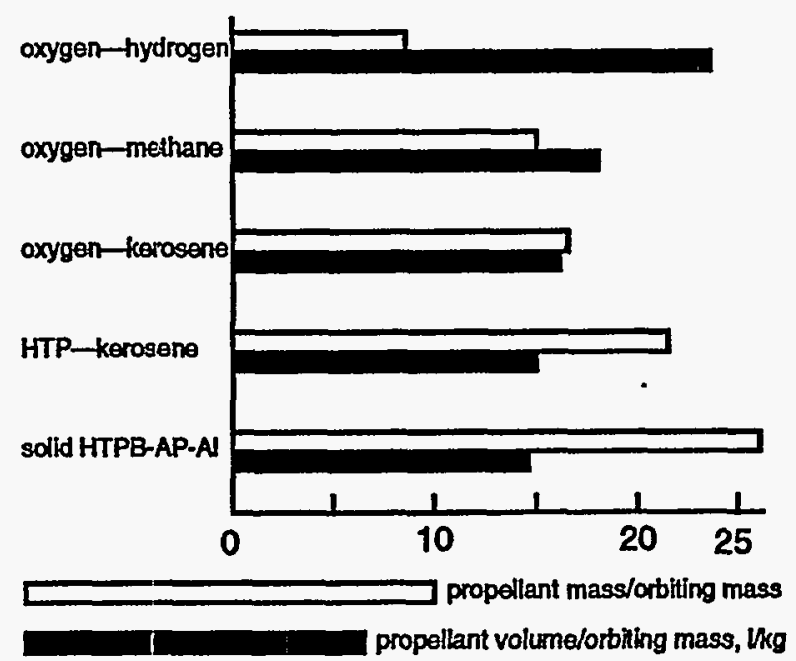

Figure 2. Propellant mass and volume have opposite trends relative to SSTO orbiting mass.

Table 1. Characteristics of candidate propellants, with mass and volume ratios required for SSTO capability

\begin{tabular}{|c|c|c|c|c|c|c|c|c|c|c|}
\hline \multirow{3}{*}{$\begin{array}{l}\begin{array}{l}\text { propellant } \\
\text { combination }\end{array} \\
\mathrm{O}_{2}-\mathrm{H}_{2}\end{array}$} & \multirow{2}{*}{\multicolumn{2}{|c|}{$\begin{array}{l}\text { O/F ratios } \\
\text { mass vol }\end{array}$}} & \multirow{2}{*}{\multicolumn{3}{|c|}{$\begin{array}{l}\text { soecilic aravity } \\
\text { ox fuel bulk }\end{array}$}} & \multirow{3}{*}{$\begin{array}{l}\text { Vacuum } \\
\text { Isp }(\theta=40) \\
452 \mathrm{sec}\end{array}$} & \multicolumn{3}{|c|}{ mass ratios to achieve $10 \mathrm{~km} / \mathrm{s} \Delta \mathrm{y}$} & \multirow[b]{2}{*}{ prop vol. } \\
\hline & & & & & & & $\begin{array}{l}\text { launch } \\
\text { orbiling }\end{array}$ & $\begin{array}{l}\text { Dropellant } \\
\text { Orbiting }\end{array}$ & $\begin{array}{l}\text { propellant } \\
\text { Jaunch }\end{array}$ & \\
\hline & 6.00 & 0.37 & 1.14 & .071 & .363 & & 9.6 & 8.6 & .895 & $23.7 \mathrm{Vkg}$ \\
\hline $\mathrm{O}_{2}-\mathrm{CH}_{4}$ & 3.45 & 1.25 & 1.14 & .415 & .821 & 369 & 15.9 & 14.9 & .937 & 18.1 \\
\hline$O_{2}-R P-1$ & 2.77 & 1.96 & 1.14 & .810 & 1.03 & 358 & 17.3 & 16.3 & .942 & 15.8 \\
\hline $98 \% \mathrm{H}_{2} \mathrm{O}_{2}-J P-5$ & 7.00 & 4.01 & 1.43 & .820 & 1.31 & 327 & 22.7 & 21.7 & .956 & 15.2 \\
\hline$H T P B-A P-A I$ & & & & & 1.8 & 310 & 26.9 & 25.9 & .963 & 14.4 \\
\hline
\end{tabular}


However, the density variation among propellants results in the opposite trend for propellant volume. For a given orbiting mass, the denser propellants require smaller tanks and hence smaller vehicles, in spite of being heavier at launch due to reduced specific impulse. The oftenoverlooked importance of propellant density can thus be appreciated at the outset. The key issue to be addressed in sections below is the fraction of orbiting mass which must be allocated to propulsion hardware (engines, tanks) and residual fluids for the various propellant choices.

\section{Engines}

Numerous existing rocket engines having thrust levels in the 0.5-2 MN range are of interest here because these have the highest demonstrated thrust-to-weight ratios. This ratio at sea level is typically near 50 for oxygen-hydrogen propellants, and near 100 for oxygen-hydrocarbon propellants. 6 This significant variation results from propellant properties, since low-density propellants (particularly liquid hydrogen) require larger flow passageways and larger, more powerful pumps.

Figure 3 shows thrust-to-weight ratios for some existing engines. Those powered by oxygen and hydrogen are the $\mathrm{J}-2$ flown on the Saturn V vehicle, 7 the Vulcain engine developed for Ariane 5,8-9 the LE-7 on Japan's H-II launcher, 10 the RD-0120 Energia core engine, 11 and the Space Shuttle Main Engine.7 Examples of oxygenkerosene engines include the $\mathrm{H}-1$ which lifted the Saturn IB,7 the RS-27 used on Delta,9\&12 and the NK-33 developed for the N-1 Russian moon vehicle. ${ }^{13}$ As the graph indicates, all these examples are consistent with the thrust-to-weight ratios indicated above and listed in Table 2 for oxygen-hydrogen and oxygen-kerosene engines.

Although there have been launchers which used the lesscommon propellants under consideration here, 14 there are essentially no such engines in the thrust class (and hence thrust-to-weight capability) discussed above. Therefore, the estimated ratios in Table 2 are based on interpolation or extrapolation depending on propellant density.

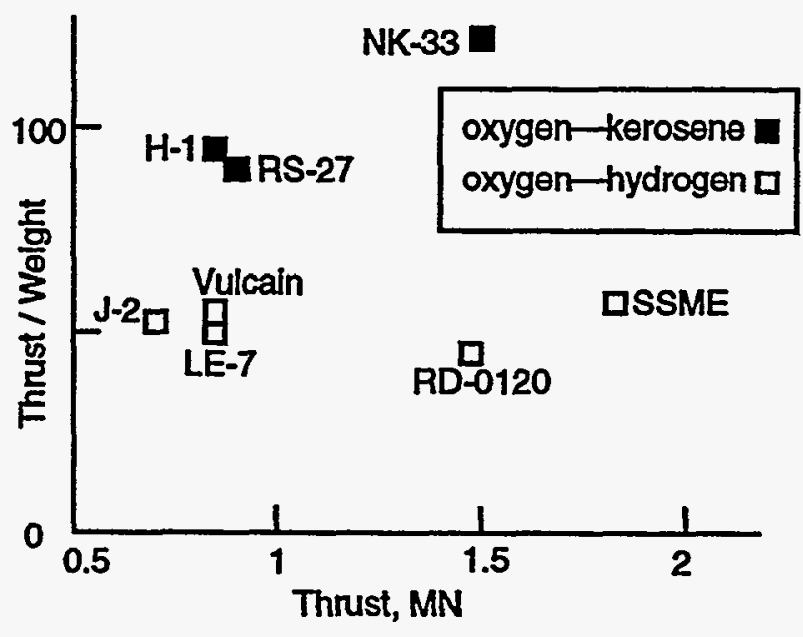

Figure 3. Rocket engine performance at sea level.

In Table 2, the first column is obtained from Table 1 . For each propellant combination, the launch-to-orbiting mass ratio is multiplied by 1.3 , the factor by which sea level thrust is assumed to exceed gross launch weight. The result is then divided by the engine thrust-to-weight ratio. This quotient is simply the fraction of SSTO vehicle orbiting mass which must be devoted to engines.

The last column in Table 2 reveals that the advantage of higher engine thrust-to-weight ratios enabled by high propellant density is almost exactly canceled by the need to lift a greater weight of these low-Isp propellants. Given proven engine technology, approximately one quarter of SSTO orbiting mass would be engines. This holds over a wide range of propellants, none of which is strongly favored for the SSTO mission on the basis of engine mass alone.

\section{Iable 2. Engine ratios for candidate SSTO propellants}

\begin{tabular}{|c|c|c|c|}
\hline $\begin{array}{l}\text { propeltant } \\
\text { combination }\end{array}$ & $\begin{array}{l}\text { launch mass } \\
\text { orbiting mass }\end{array}$ & $\begin{array}{l}\text { sea level thrust } \\
\text { enoine weight }\end{array}$ & $\frac{\text { dru enoine mass }}{\text { vehicle orbitine mass }}$ \\
\hline $\mathrm{O}_{2}-\mathrm{H}_{2}$ & 9.6 & 50 & 0.25 \\
\hline $\mathrm{O}_{2}-\mathrm{CH}_{4}$ & 15.9 & 90 & 0.23 \\
\hline$O_{2}-R P-1$ & 17.3 & 100 & 0.22 \\
\hline $\mathrm{H}_{2} \mathrm{O}_{2}-\mathrm{JP}-5$ & 22.7 & 120 & 0.25 \\
\hline
\end{tabular}


Tanks

From thin-wall pressure vessel theory, the ratio of propellant mass to tank mass is expected to be proportional to propellant density, given a constant pressure and fixed material properties. The lack of any fundamental dependence on absolute size is a key fact that was recognized during the early days of liquid rocketry. ${ }^{15}$

It might be argued that hydrogen tanks are relatively lighter than simple equations predict, due to the lower contribution of elevation pressure (head) to structural loading. One might alternatively argue that such larger tanks would be heavier, due to greater bending moments on longer vehicles. The known weights and propellant capacities of existing launcher tanks indicate that these effects are minor. To within ten percent, the performance (as defined in Figure 4) of real tanks is proportional to propellant density, and independent of size.

In the past, the common-bulkhead Atlas tank assembly contained just over 100 times its mass in oxygen-kerosene, which has a bulk specific gravity just above 1.16 Atlas walls have gotten thicker over the years to carry bending moments in lengthened vehicles which no longer have optimum aspect ratios. The current Atlas II holds a propellant mass 90 times that of the tanks. 17 Centaur tanks use the same technology, but carry only 35 times their weight in oxygen-hydrogen. 18

Historically, some aluminum tanks were less efficient than the Atlas-Centaur stainless steel tanks. ${ }^{19}$ Note that associated structures such as intertanks, thrust structures, and skirts, are not counted here. The Saturn V first stage fuel tank carried 64 times its structural weight (excludes oxygen tunnels) in RP-1, so it would hold 79 times its weight in water, based on the specific gravity ratio. Similarly, its counterpart would have held 82 times its weight in water, and actually contained 93 times its weight in liquid oxygen. The S-II and S-IVB upper stage tank assemblies were lighter, with water-to-tank mass ratios between 90 and 100.20

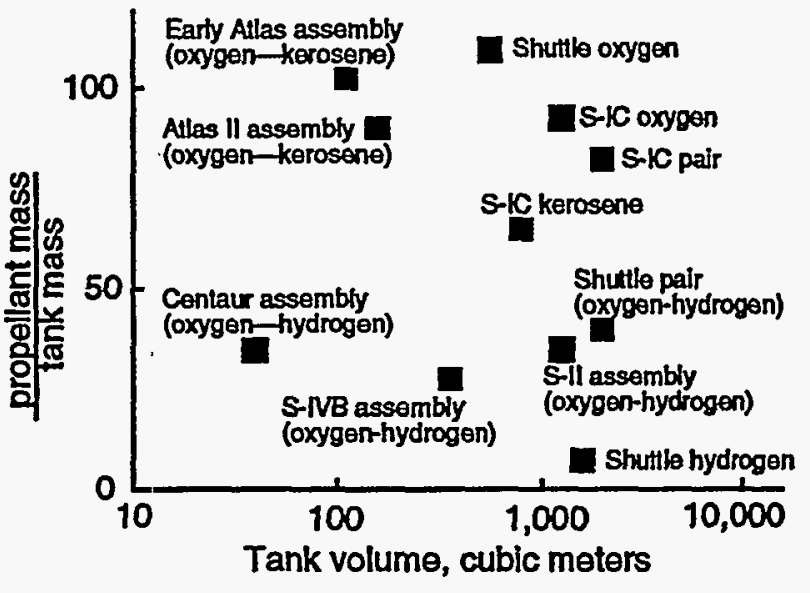

Figure 4. Historical launch vehicle tank performance.

The Shuttle aluminum oxygen tank now holds 118 times its weight in oxygen. 21 The ratio is only 8 for the larger Shuttle hydrogen tank, which is consistent with hydrogen's specific gravity of .07 . Finally, the combined propellant-totankage mass ratio for the Shuttle is 40 , similar to that of the much smaller Centaur. The masses of the intertank, feedlines, and other subsystems of the Shuttle External Tank are omitted here. If insulation is included, the combined Shuttle tank performance falls to 36 .

From the above examples as plotted in Figure 4, it is evident that "1\% tankage" exists over a wide range of sizes for dense propellants. The graph also illustrates the strong effect of reducing density. Based on this historical data, the ratios of propellant mass to tank mass are simply assumed to be 100 times the bulk specific gravity. The results are given in the second column of Table 3. Dividing the first column (borrowed from Table 1) by the second yields the fraction of each SSTO vehicle's orbiting mass which must be reserved for propellant containers.

The last column in Table 3 has profound implications. Based on historical tank capabilities, nearly one quarter of the all-cryogenic SSTO orbiting mass must be tankage. However, SSTO vehicles designed for kerosene fuel need only allocate one-sixth of their orbiting mass to tankage.

\section{Table 3. Tank mass ratios forcandidate propellants}

\begin{tabular}{lccl}
$\begin{array}{c}\text { propellant } \\
\text { combination }\end{array}$ & $\begin{array}{c}\text { propellant mass } \\
\text { orbifina mass }\end{array}$ & $\begin{array}{c}\text { propellant mass } \\
\text { tankmass }\end{array}$ & tank mass \\
\hline $\mathrm{O}_{2}-\mathrm{H}_{2}$ & 8.6 & 36 & 0.24 \\
$\mathrm{O}_{2}-\mathrm{CH}_{4}$ & 14.9 & 82 & 0.18 \\
$\mathrm{O}_{2}-\mathrm{RP}-1$ & 16.3 & 103 & 0.16 \\
$\mathrm{H}_{2} \mathrm{O}_{2}-\mathrm{JP}-5$ & 21.7 & 131 & 0.16
\end{tabular}


Tank pressurization

Ullage gases and pressurant storage bottles are the major contributors to tank pressurization mass. This mass is of interest here because it depends on tank volume, and hence propellant characteristics. Data are summarized in Table 4 fơr several stages which have undoubtedly reduced their pressurization mass requirements to reasonable limits.

The Space Shuttle uses $1280 \mathrm{~kg}$ of gaseous oxygen, and $460 \mathrm{~kg}$ of gaseous hydrogen, for flight pressurization at roughly $0.2 \mathrm{MPa}$. 21 These quantities are $0.20 \%$ and $0.44 \%$ of the total oxidizer and fuel loads, respectively. These percentages would not be expected to differ given identical ullage pressures and temperatures, because the molecular weight ratio of oxygen to hydrogen equals their liquid density ratio. In practice, the doubled pressurant fraction for hydrogen is indicative of the higher pressure and lower temperature of the fuel ullage. The resulting mass penalty is small because most of the Shuttle's propellant mass is oxygen. The total pressurant mass in the discarded External Tank is $0.24 \%$ of the initial propellant, as indicated in the last column of Table 4.

The S-IC stage which lifted astronauts toward the moon needed to boil slightly more of its oxygen than the Shuttle does, as listed in the table. ${ }^{20}$ Kerosene does not readily boil, however, so helium stored in bottles was used to pressurize the fuel. These 4 bottles were located inside the oxygen tank which kept them cold, to increase the helium packing density as well as the strength of the aluminum. ${ }^{22}$ Although the helium itself was extremely lightweight, the tank mass increased the pressurization mass considerably. To permit fair comparisons among the different launchers, Table 4 neglects other hardware in the helium pressurization system.
Atlas uses helium, stored initially at $80 \mathrm{~K}$, to pressurize both main tanks. The storage mass listed in Table 4 includes 10 spherical tanks and their cooling shrouds which contain liquid nitrogen before launch. 17

For oxygen tank pressurization, Ariane 5 stores helium close to its liquid state in a $1.3 \mathrm{~m}$ diameter sphere. ${ }^{23}$ The pressurant and its storage hardware amount to $0.30 \%$ of the loaded oxidizer.?

The pressurant fractions in the last column of Table 4 are quite similar over a wide variety of launch vehicles, with differences mostly attributable to differences in tank pressures. There is little direct dependence on propellant density for three reasons. Firstly, lightweight hydrogen gas is used to pressurize liquid hydrogen, so pressurant mass does not scale with its high liquid volume. Secondly, the densities of the other common propellants are close to each other. Thirdly, the molecular weight ratio of oxygen to helium is similar to the weight ratio of tanks of helium to usable helium, so these two pressurization options yield similar results.

Low-density methane would be pressurized by its own relatively lightweight vapor, so it is assumed to follow the historical trend. The assumption used below is that pressurants (and their storage tanks, if any) mass $0.25 \%$ of the propellants. The high density of hydrogen peroxide results in a $-20 \%$ pressurant advantage, so $.20 \%$ of the HTP-kerosene mass is assumed. As will be seen, small errors are of higher order because pressurization mass is smail relative to tanks and engines.

Table 4. Tank pressurization mass for existing hardware

\begin{tabular}{|c|c|c|c|c|c|}
\hline $\begin{array}{l}\text { launch vehiclo } \\
\text { and stace }\end{array}$ & $\begin{array}{l}\text { propollant and tis } \\
\text { mass at Jaunch. fons }\end{array}$ & $\begin{array}{l}\text { ullage gas and } \\
\text { final mass. fons }\end{array}$ & $\begin{array}{l}\text { final_ullage mass } \\
\text { Initial prop mass }\end{array}$ & $\begin{array}{l}\text { pressurant } \\
\text { storage mass tons }\end{array}$ & $\begin{array}{l}\text { tolal pross, mass } \\
\text { initial prop. mass }\end{array}$ \\
\hline Shuttle & oxygen, 629 & oxygen, 1.28 & .0020 & negligible & .0020 \\
\hline Shutte & hydrogen, 105 & hydrogen, 0.46 & .0044 & negligible & .0044 \\
\hline Shuttle & lotal, 734 & total, 1.74 & .0024 & negligible & .0024 \\
\hline Satum V, S-1C & oxygen, 1505 & oxygen, 3.44 & .0023 & negligible & .0023 \\
\hline Satum V, S-K & kerosene, 652 & hollum, 0.32 & .0005 & 2.18 & .0038 \\
\hline Satum V, S-lc & total, 2157 & total, 3.76 & .0017 & 2.18 & .0028 \\
\hline Atlas II core & total, 166 & helium, 0.13 & .0008 & 0.42 & .0035 \\
\hline Ariane 5 core & oxygen, 130 & helium, 0.14 & .0011 & 0.25 & .0030 \\
\hline
\end{tabular}


Iable 5. Residual liquid mass for existing launchers

\begin{tabular}{|c|c|c|c|c|c|c|}
\hline $\begin{array}{l}\text { launch vehicle } \\
\text { and slace }\end{array}$ & $\begin{array}{l}\text { total propellant } \\
\text { mass tons }\end{array}$ & $\begin{array}{l}\text { residual } \\
\text { oxidizer.tons }\end{array}$ & $\begin{array}{l}\text { residual } \\
\text { fuel.tons }\end{array}$ & $\begin{array}{l}\text { total residual } \\
\text { liquid. tons }\end{array}$ & $\begin{array}{l}\text { tote } \\
\text { tote }\end{array}$ & $\begin{array}{l}\text { esidual lould } \\
\text { nitial propellant }\end{array}$ \\
\hline Shuttle & 734 & .91 & .47 & 1.38 & '(unusable only) & .0019 \\
\hline Shuttie & 734 & .91 & .99 & 1.90 & (incl. MR bias) & .0026 \\
\hline Shuttle & 734 & 2.39 & 1.23 & 3.62 & (flight actual) & .0049 \\
\hline Satum V, S-1C & 2157 & 13.9 & 12.2 & 26.1 & (flight predicted) & .0121 \\
\hline Satum , S-1! & 453 & 1.3 & 1.4 & 2.7 & (flight predicted) & .0060 \\
\hline Allas II core & 156 & 0.15 & 0.10 & 0.25 & (flight actua) & .0016 \\
\hline
\end{tabular}

\section{Residual liquid propellants}

In general, residual liquid includes both reserve propellant, and the unusable propellant which remains on internal tank surfaces, in pipes, and in engines. For example, engine pumps often rely on feedline head from upper tanks to provide adequate suction pressure. The result is that feedline propellant cannot be used. Liquid which is deliberately kept in reserve includes enough for contingency maneuvers as well as a fuel excess to ensure mixture ratio (MR) control.

The External Tank (ET) mass properties report provides a detailed breakdown of propellants remaining in the ET components at separation from the Orbiter. 21 This includes unusable propellant, a hydrogen reserve (MR bias), and a flight performance reserve of both fuel and oxidizer. ${ }^{24}$ Three sets of numbers for the Space Shuttle are listed in Table 5.

Detailed listings of liquid masses in tanks and feedlines for the Saturn V is available for both early and late Apollo missions. $20 \& 25$ The later improved numbers are used here. The entries in Table 5 for the first two stages represent the total liquid residuals at stage separation. The Saturn residuals include a fiel bias for both stages shown, and are higher than the Shuttle residuals. In the S-IC, most of the residual oxygen was in the five huge conduits which ran through the kerosene tank. The fuel residual was divided roughly evenly between the tank and components below the tank. In the S-II, the liquid fuel residual was almost entirely in the (upper) tank, whereas over half of the liquid oxygen residual was in the lines and engines.

The Atlas II thrusts until the oxygen pump cavitates. ${ }^{17}$ The residuals are biased toward kerosene, to ensure that the correct mixture is maintained.

In Table 5, residual liquid fractions vary widely, depending on vehicle design and mission requirements. It is noteworthy that the hydrogen residuals for both the Shuttle and S-II are way out of proportion to the mixture ratio. However, there is no strong dependence on propellant density when the overall residuals are considered. In particular, note that the unusable fractions for the Shuttle and Atlas II are very similar. Although the Saturn residuals are higher than the best demonstrated numbers, this is so for both the kerosene and hydrogen stages. For the purpose of the present analysis, $.25 \%$ is chosen as a round number near the low end of the range of proven capability.

Given the chosen assumptions for tank pressurization and residual liquid, Table 6 lists the resulting fractions of SSTO orbiting mass for the different propellants. These two contributions amount to $0.5 \%$ of propellant mass at launch (.45\% for HTP-JP-5), so the higher Isp propellants are favored here.

$\begin{array}{lc}\text { Table 6. Pressurization }+ \text { residual liquid mass ratio } \\ \begin{array}{l}\text { propellant } \\ \text { cembination }\end{array} & \text { pressurization mass + residual liauid mass } \\ \mathrm{O}_{2}-\mathrm{H}_{2} & .043 \\ \mathrm{O}_{2}-\mathrm{CH}_{4} & .075 \\ \mathrm{O}_{2}-\mathrm{RP}-1 & .082 \\ \mathrm{H}_{2} \mathrm{O}_{2}-\mathrm{JP}-5 & .098\end{array}$

\section{SSTE orbiting mass summary}

Figure 5 summarizes the data from the last columns of Tables 2, 3, and 6. Approximately half the orbiting mass must be allocated to engines, tanks, and fluids (including pressurant bottles, if any). The amazing result is that the dependence on propellant choice is rather weak. The range is from $53 \%$ for the all-cryogenic option, to $46 \%$ for oxygen and kerosene. This analysis indicates that a kerosene-fueled SSTO vehicle needs to devote less of its orbiting mass to propulsion, than if hydrogen is the fuel. 


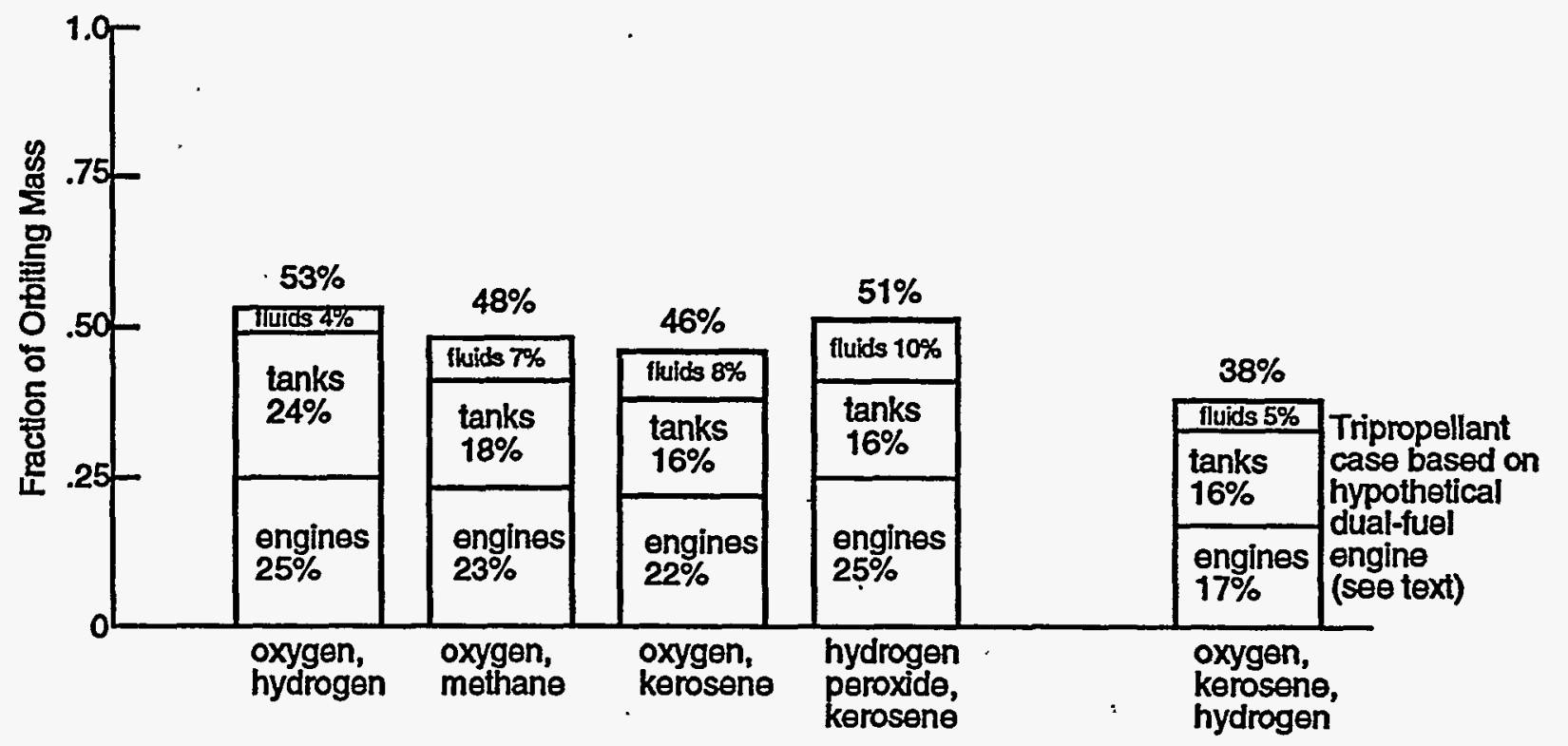

Figure 5. SSTO propulsion mass budgets for several propellant combinations.

Figure 5 represents scaleable propulsion conceptual designs for SSTO, within the capabilities of flight-proven liquid propulsion hardware. This graph shows the fractions of vehicle orbiting mass which must be reserved for major components whose masses depend strongly on propellant properties. The remaining part of each mass budget must accommodate the payload and all other subsystems, including structure, feedlines, thermal protection, auxilliary power, avionics, control systems, safety systems, aero surfaces, landing gear, cockpit, life support, etc. Although Figure 5 may suggest that SSTO performance is easy to achieve, there is very stiff competition indeed for this remaining half of the orbiting mass. For example, non-tank structure is relatively heavy, as discussed in a later section.

Advancing technology may reduce hardware weight below flight-proven values. In this event, the mass allocations would logically fall proportionately across the propellant range. Thus even if the numbers become outdated, Figure 5 provides a comparative analysis to aid in choosing SSTO propellants. Similarly, reducing $\Delta v$ to $9 \mathrm{~km} / \mathrm{s}$ resulted in the same relative propellant ranking as in Figure 5, with roughly $40 \%$ of orbiting mass allocated to propulsion.

\section{Tripropellant option}

A vast improvement can theoretically be obtained by burning kerosene at liftoff for low engine weight and tankage volume, but later switching to hydrogen so that the initial gross weight to be lifted (i.e. thrust) is reduced below that of an oxygen-kerosene vehicle. This is fundamentally the same strategy used by Saturn, Atlas-Centaur, and
.Energia, except that these multi-stage vehicles also jettison. hardware associated with the dense booster propellants. The use of both hydrogen and hydrocarbon fuels in a single stage vehicle has previously been considered in terms of its beneficial effect on payload as a function of gross launch weight. ${ }^{26}$ Figure 5 includes a representation of a dual-fuel SSTO design from the present perspective. The major propulsion components require just $38 \%$ of the orbiting mass.

The dual-fuel component masses in Figure 5 were calculated using a one-page computer spreadsheet, in which the $\Delta \mathrm{v}$ split could be varied (total $10 \mathrm{~km} / \mathrm{s}$ ). The masses of tankage and fluids were determined using the rules presented previously. The engines were assumed to be capable of accepting either fuel, with a $10 \%$ weight penalty relative to an oxygen-kerosene engine, to account for the hydrogen pump etc. An iterative process resulted in the values listed in Table 7 and the result shown in Figure 5.

\section{Table 7. Tripropellant case}

$\begin{array}{lr}\text { oxygen-kerosene } \Delta v & 3600 \mathrm{~m} / \mathrm{s} \\ \text { oxygen-hydrogen } \Delta v & 6400 \mathrm{~m} / \mathrm{s} \\ \text { launch mass / orbiting mass: } & 11.8 \\ \text { mass at fuel switchover/orbiting mass: } & 4.2 \\ \text { oxygen mass / orbiting mass: } & 8.4 \\ \text { kerosene mass / orbiting mass: } & 2.0 \\ \text { hydrogen mass / orbiting mass: } & 0.5 \\ \text { engine thrust / welght (oxygen-kerosene, S.L.): } & 90\end{array}$


A dual-fuel approach increases complexity for tankage, structure, feedlines, and launch operations, which can reduce reliability. A tripropellant engine is a significant technical challenge yet to be demonstrated, and the thrustto-weight ratio assumed above is quite optimistic. Additionally, hydrogen flow is likely to be required during the kerosene burn, 27 which reduces the benefit. An alternative would be to use separate hydrogen engines. However, their weight would cancel the advantage of the dual-fuel vehicle, even though they would need to push less than a third of the launch mass.

\section{Additional propellant choice considerations}

A number of minor factors have not been quantified herein, but are nevertheless worthy of mention. Dense propellants can reduce gravity losses by delivering higher average acceleration over shorter burn times. This is evident upon considering that minimum burn time nearly equals Isp, if both propellant fraction and initial thrust-to-weight ratio are close to unity.

Larger vehicle surface area can increase both drag and the weight of thermal protection, which favors dense propellants.

Non-cryogenic propellants don't need insulation, which permits lightweight common bulkheads between hydrogen peroxide and kerosene. The latter is true for oxygen and methane, although external insulation may be needed. Operations with non-cryogenic propellants can be less complex and costly than with cryogens.

Worldwide experience with oxygen-kerosene greatly exceeds experience with other liquid propeliants, so implementation may be less costly.

Fitting adequate engines into a vehicle's base area may be more difficult with kerosene than with hydrogen fuel.

The advantage of hydrogen fuel is a large reduction in gross launch weight. This is a consideration if wings must lift the vehicle when full (horizontal takeoff), or if it must land after an early abort. Even with hydrogen, however, these possibilities seem remote; not even airliners are structurally rated to land when full of fuel.

The structure needed to carry thrust loads or to support a loaded vehicle before launch is reduced by using hydrogen, but aggressive design should absolutely minimize such structural elements.

Another reason to choose hydrogen for SSTO gross weight reduction is the flexibility for operation as an upper stage.
Non-tank structure

As was the case for individual propulsion components above, structural engineering insight can be gained from flight-proven hardware. Cross sections of the tanks and some associated structures of a few real stages are sketched to scale in Figure 6. It is clear from the component mass labels that non-tankage structure has significant mass relative to tanks. ${ }^{17 \& 20-22}$

The Atlas, which is dwarfed by the larger tanks in Figure 6, minimizes extra structure by using a common bulkhead instead of an intertank. Similarly, the upper stages of the Saturn V used common bulkhead tanks. ${ }^{28}$ This is an important point, because the weight of non-tank cylindrical structures, per unit vehicle length, historically exceeds that of tank walls. For example, the S-IC oxygen and kerosene tank cylindrical walls massed $646 \mathrm{~kg} / \mathrm{m}$ and $582 \mathrm{~kg} / \mathrm{m}$ respectively, whereas the forward skirt and intertank were $20-50 \%$ heaviex per unit vehicle length at $768 \mathrm{~kg} / \mathrm{m}$ and 894 $\mathrm{kg} / \mathrm{m}$. It is additionally significant that these nonpressurized structures were made of a stronger alloy (Al7075) than the tanks (A1-2219). ${ }^{29}$

In the Shuttle ET, the intertank structure (at $807 \mathrm{~kg} / \mathrm{m}$ ) actually weighs more than the entire oxygen tank. This is significant, given that the total surface area of the tank appears to be nearly twice that of the intertank (Figure 6). Some of the weight is needed by the intertank to carry thrust loads between the solid boosters, ET, and Orbiter.

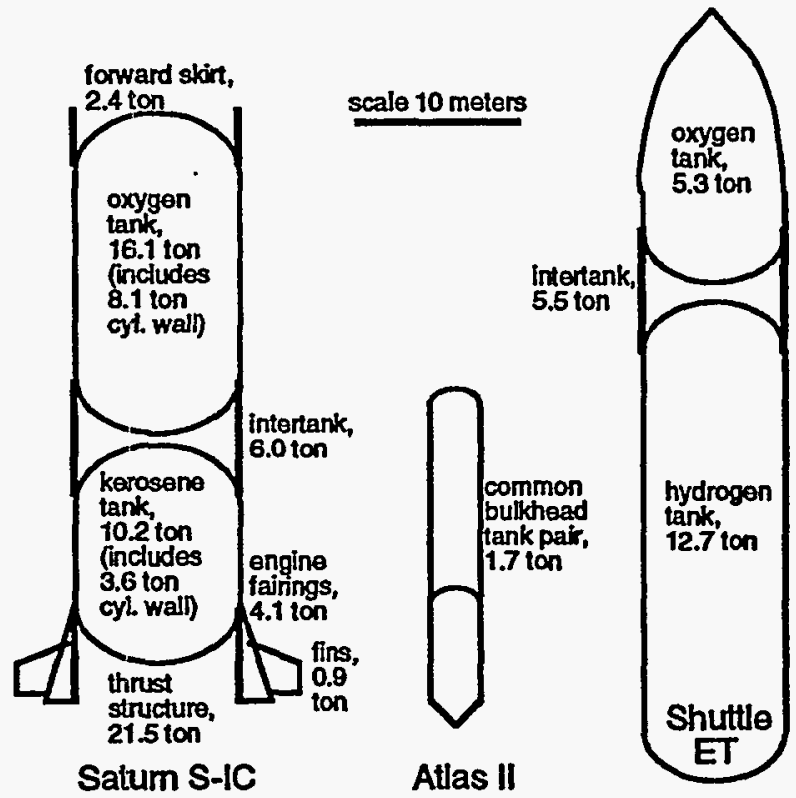

Figure 6. Non-tankage structures are historically heavy. 
However, non-tank structures must generally be heavy to accommodate compressive flight loads. The structural capability of tanks is enhanced by internal pressure, even though the stiffeners used in a'uminum tanks permit unpressurized ground bandling.

Considering this historical perspective, it is evident in view of Figure 5 that non-tank structures should be used sparingly in SSTO designs. If flight-proven structural technology is used, such a vehicle must essentially be a flying tank pair, just like stages of conventional launchers. Conversely, if a SSTO vehicle is to be substantially different from a flying tank pair, structural capability needs to be greatly improved. For example, a total amount of non-tank structure similar in size to the tanks would be possible if advanced structural technology permits tanks to hold 200 times their own mass in water. Even greater advances are required in order to carry tanks as separate items inside a SSTO vehicle, as is occasionally proposed.

\section{Twe approaches to realizing reusable SSTO}

The concept of single-stage-to-orbit capability is widely associated with the notion of reusable launch vehicles, because the ultimate goal is to combine the two. In reality, designing for reusability initially requires robust hardware which is too heavy to reach orbit without staging.

Not even a fragile expendable vehicle has ever reached earth orbit without dropping hardware off. Since reusability. and SSTO performance are conflicting requirements, it is logical to first develop these capabilities independently.

Currently, several programs are approaching the problem from the reusability standpoint. This approach saves money by permitting repeated testing with the same vehicle. This hardware-saving feature may also be a disadvantage, by discouraging revolutionary redesign.

The challenge of demonstrating SSTO could be separately addressed by flying prototype high-mass-ratio vehicles which are expendable, and as smail and cheap as possible. An advantage to flying expendable vehicles is that major design advances are possible on every flight. An advantage to flying smaller vehicles is that aggressive designs (e.g. to eliminate non-tank structure) can be tested with less at stake (smaller explosions). Hopefully, the historical data presented in this paper will help to dispel the myth that vehicles must be scaled up in absolute size to achieve SSTO mass ratios. In view of Figure 5, it seems logical to use kerosene fuel for expendable SSTO experimental flights.
Such a development program which expends test vehicles should demonstrate excess payload-to-orbit capacity, before any flying mass is allocated to reentry, landing, or re-use capabilities. There is another way to view this fraction of orbiting mass which is borrowed from recovery functions. This "bonus mass" should initially be used to offset the practical limitations of scaling down to small experimental vehicles, and/or choosing non-optimum propellants to reduce costs (e.g. HTP-kerosene). ${ }^{30}$

Of the two different approaches to developing a reusable SSTO vehicle, the first provides a direct path to the goal only if materials advances permit large weight reductions without vehicle redesign. In contrast, the second approach is necessary if the solution turns out to depend on aggressive design more than on materials research.

\section{Discussion}

The methodology used herein amounts to comparing conceptual vehicle designs. Therefore, the results (Figure 5) may be refined using higher fidelity fractional mass estimates, and non-propulsion subsystems can also be included on the same graph. Ultimately, complete SSTO designs may be compared side-by-side. This method is additionally useful for comparing the payload fractions of rocket propelled and air-breathing SSTO vehicle designs.

Historical hardware capabilities are remarkably consistent over many launch vehicles from different nations, and over decades of time. Therefore it seems unlikely that these numibers can be improved upon rapidly. An example is the Shuttle's Super Light Weight Tank (SLWT) now being developed from an advanced aluminum alloy. ET weight is expected to be reduced by $10-15 \% .21$ This structural advance is significant, but it must happen many times over before SSTO vehicles will be able to have much non-tank structure.

Examples of aggressive design proven in the past include pressure-stabilized tanks, common bulkheads to eliminate intertank structures, and locating auxiliary components inside the main tanks in lieu of accommodating such components inside of lengthened skirts. Another key example related to re-entry capability is that conical or tapered tanks have been proven on the early Atlas, on Shuttle, and on the Soyuz strap-on boosters. The use of a greater number of engines can shorten the length of associated skirt structure, when compared with using one or a few large engines. 


\section{Summary of key points}

1. A SSTO vehicle is a first stage. Its gross launch weight is less important than that of upper stages. For example, hydrogen fuel greatly reduces gross weight, but first stages historically have not used hydrogen.

2. The mass and size of rocket hardware is strongly affected by propellant density as well as specific impulse. For example, tank mass depends on volume, not propellant mass. Also, hydrocarbon engines historically weigh about half as much as hydrogen engines, for a given thrust level.

3. Hydrocarbon-fueled SSTO rocket vehicles are dimensionally more compact than those using hydrogen, for a given total mass on orbit.

4. Given flight-proven rocket hardware capabilities, about half of SSTO orbiting mass is needed for engines, tanks, and fluids, over a wide range of real propellants.

5. Based on historically-proven launch vehicle hardware, liquid oxygen and kerosene appear to be a preferred propellant combination for SSTO. Of all the propellants considered, these require the smallest fraction of orbiting mass for major propulsion components.

6. Hydrogen-fueled SSTO vehicles must allocate a slightly greater fraction of their orbiting mass to propulsion, because hydrogen tanks are large and hydrogen engines have a low thrust-to-weight ratio.

7. Dual-fuel operation can dramatically reduce the propulsion fraction of SSTO orbiting mass. The net result is analogous to an Atlas-Centaur constructed of hardware light enough that none needs to be dropped. This possibility depends on the thrust-to-weight ratio of dualfuel engines yet to be developed.

8. Rocket performance including SSTO feasibility depends fundamentally on ratios, more than on absolute size. For example, history records constant tank performance over nearly 2 orders of magnitude in volume.

9. Eliminating non-tankage structure enables SSTO mass ratios with existing technology. Experiments with aggressive designs could be conducted on a reduced scale, for less costly flight losses and one-way trips to orbit.

10. Any new structural technology for launch vehicles must significantly surpass the 4-decades-old capability of tanks to contain 100 times their own mass in water. A great advance is needed before it is meaningful to consider SSTO vehicles that have significant structure in addition to tanks.

\section{Acknowiedgments}

In addition to those individuals listed in the references, the following provided accessibility to historical data used herein: Terry Bohlen at Lockheed-Martin (Atlas), Mike Wright at the NASA Marshall Space Flight Center, Jim Gamett at Lockheed-Martin (Shuttle ET, ex Saturn team), and Tibor Lak at Rockwell (Shuttle). Thanks to Preston Carter, Jordin Kare, Fred Mitlitsky, and George P. Sutton for comments on the manuscript.

This work was sponsored by the U.S. Government and performed by the University of California Lawrence Livermore National Laboratory under Contract W-7405Eng-48 with the U.S. Dept. of Energy.

\section{References}

1. Stanley, D.O., et al, Rocket Powered Single Stage Yehicle Configuration Selection and Design, J. Spacecraft \& Rockets, 31(5), Sept-Oct 1994.

2. Clapp, M.B., and M.W. Hunter, A Single Stage to Orbit Rocket with Noncryogenic Propellants, AIAA 93$2285,1993$.

3. Hunter, M., The SSX: Hydrogen vs Hydrocarbons. Space Guild internal memorandum nr SG-00098, Dec 1988.

4. Hunter, M., The SSX - A True Spaceship. Journal of Practical Applications in Space, 1(1), pp. 41-62, 1989.

5. Sponable, J.M., Assessing Single Stage to Orbit Eeasibility, AIAA 95-3004, 1995.

6. McHugh, B., Numerical Analysis of Existing Liquid Rocket Fngines as a Design Process Starter, AIAA 95$2970,1995$.

7. Fisher, M.F., A Saturn Launch Vehicle and STS Bropulsion System Primer, NASA George C. Marshall Space Flight Center, 1995.

8. Brossel, P., et al, Development Status of the Vulcain Engine AIAA 95-2539, 1995.

9. Isakowitz, S.J., International Reference Guide to Space Launch Systems, 2nd Ed, AIAA, 1995.

10. Fukushima, Y., Imoto, T., Lessons Leamed in the Development of the LE-5andLE-7. AIAA 94-3375, 1994. 
11. Rachuk, V.S., et al, Design. Development. and Histocy of the Oxygen/Hydrogen Engine RD-0120, AIAA 95-2540, 1995.

12. CPIA, Delta II Launched, Chemical Propulsion Information Agency Bulletin, Vol 18 nr 5, Johns Hopkins University, Sept 1992.

13. Lacefield, T.C., W.J. Sprow, High_Performance Bussian NK-33 LOX/Kerosene Liquid Rocket Engine, AIAA 94-3397, 1994.

14. - Parkin, L.W., The Performance of Black Arrow in the Launch of the Prospere Satellite, Journal of the British Interplanetary Society, 28, pp 263-277, 1975.

15. Shesta, J., Construction of Tanks-No Matter How Large Cubic Capacity Per Pound of Tank Remains Constant, Astronautics 8(39) pp 13-16, January 1938.

16. Martin, R.E., The Atlas and Centaur Steel Balloon Tanks:-A Legacy of Karel Bossart, IAA-89-738, 40th International Astronautical Congress, 1989.

17. Hazard, R, Private Communication, Lockheed-Martin Astronautics, 1996.

18. Richards, G.R., J.W. Powell, The Centamr Vehicle, Journal of the British Interplanetary Society, p. 99, 1989.

19. Midgley, P., Structural Materials for Use at Cryogenic Temperatures, Journal of The British Interplanetary Society, 23, pp 597-606, 1970.

20. NASA, Saturn V/AS-511 Operational Mass Characteristics (Apollo 16 Mission), Marshall Space Flight Center, Sept 1971.

21. Johnson, J.H., L.L. Hartley, G.A. Edmonson, Space Shuttle External Tank Mass Properties Status Report, report nr. MMC-ET-SE02-126, Lockheed Martin Corp, Sep 15, 1995.

22. Boeing, S-IC Stage Structures, NASA report R-SE-L 040-007, Marshall Space Flight Center, 1968.

23. Teissier, A., Liquid Helium Storage for Ariane 5 Main Stage Oxygen Tank Pressurization, AIAA 95-2956, 1995.

24. Norquist, L., Extemal Tank for the Space Shuttle Main Propulsion System. Journal of Spacecraft and Rockets 14(6), pp. 358-364, June 1977.
25. NASA, Saturn V Launch Vehicle Flight Evaluation Report AS-503. Apollo 8 Mission, MPR-SAT-FE-69-1, "Section 21, Mass Characteristics," microfiche nr N6924692, Feb 20, 1969.

26. Salkeld, R., Mixed-Mode Propulsion for the Space Shuttle, Astronautics \& Aeronautics, 9, pp 52-58, August 1971.

27. Rachuk, V.S., et al, The RD-0120 Has Great Potential for Low Cost Reusable Engine and for Tripropellant SSTO Yalidations, AIAA 943399, 1994.

28. Parker, W.F., Saturn S-II Operations Development Brogress, J. Spacecraft, 2(5), pp 826-827, 1965.

29. Farner, H.B., T.R. Rutkay, Eabricating the S-IC Space Booster, Welding Journal pp. 29-34, Jan 1965.

30. Kare, J.T., Mockingbird Multiple Application Rocket Drone: Technical and Brogrammatic Overview, LLNL UCRL-MI-123825, Nov. 1994. 
